Jurnal Inkofar * Volume 1 No. 2 Desember 2019 * ISSN: 2615-3645 (Print) / 2581-2920 (Online)

Tersedia secara online di: http://www.politeknikmeta.ac.id/meta/ojs/

\title{
ANALISIS KEGIATAN PENGELOLAAN SEDIAN FARMASI, ALAT KESEHATAN DAN BAHAN MEDIS HABIS PAKAI BERDASARKAN PERMENKES RI NOMOR 72 TAHUN 2016 DI RS X KABUPATEN BEKASI
}

\author{
Tisa Amalia ${ }^{1}$, Dicky Kurnia Ramadhan ${ }^{2}$ \\ ${ }^{1}$ Program Studi Farmasi/ Politeknik META Industri Cikarang/ tisa@politeknikmeta.ac.id \\ ${ }^{2}$ Program Studi Farmasi/ Politeknik META Industri Cikarang/ kurniadicky63@gmail.com
}

\begin{abstract}
One of the services available in the hospital is pharmaceutical services. Pharmaceutical services must be carried out in accordance with hospital pharmacy service standards. According to the Republic of Indonesia Minister of Health Regulation No. 72 of 2016 concerning Pharmaceutical Services Standards in Hospitals, it is stated that Pharmaceutical Services Standards are benchmarks used as guidelines for pharmaceutical personnel in carrying out pharmaceutical services. Hospital Pharmacy Services is an inseparable part of the Hospital health service system that is oriented towards patient services, the provision of quality, affordable Pharmaceutical Supplies, Medical Devices and Consumable Medical Materials for all levels of society including clinical pharmacy services. The purpose of this study was to determine the management activities of pharmaceutical preparations, medical devices and consumable medical materials based on the Republic of Indonesia Regulation No. 72 of 2016 at X Hospital Bekasi District. Research on the Analysis of Management of Pharmaceutical Products, Medical Devices and Consumable Medical Materials uses a normative juridical approach, namely by reviewing or analyzing secondary data in the form of legal materials especially primary legal materials and secondary legal materials by understanding the law as a set of regulations or norms. positive norms in the legal system that regulate human life and are supported by reality on the ground. The results of this study are the activities of managing pharmaceutical preparations, medical devices and consumable medical materials in RS $X$ Bekasi Regency in accordance with Permenkes RI No. 72 of 2016 concerning pharmaceutical service standards at the Hospital, starting from the activities of selection, planning, procurement, acceptance, storage, distribution, destruction and withdrawal of pharmaceutical preparations, medical devices and consumable medical materials, control, administration.
\end{abstract}

Keywords: Management of Pharmacy Sedian Management, Medical Devices and Consumables, Consumables, Republic of Indonesia Health Regulation Number 72 Year 2016

\begin{abstract}
ABSTRAK
Pelayanan yang ada di rumah sakit salah satunya yaitu pelayanan kefarmasian. Pelayanan kefarmasian harus dilakukan sesuai dengan standar pelayanan kefarmasian rumah sakit. Menurut Permenkes RI Nomor 72 Tahun 2016 tentang Standar Pelayanan Kefarmasian Di Rumah Sakit disebutkan bahwa Standar Pelayanan Kefarmasian adalah tolok ukur yang dipergunakan sebagai pedoman bagi tenaga kefarmasian dalam menyelenggarakan pelayanan kefarmasian. Pelayanan Kefarmasian di Rumah Sakit merupakan bagian yang tidak terpisahkan dari sistem pelayanan kesehatan Rumah Sakit yang berorientasi kepada pelayanan pasien, penyediaan sediaan farmasi, alat kesehatan, dan bahan medis habis pakai yang bermutu dan terjangkau bagi semua lapisan masyarakat termasuk pelayanan farmasi klinik. Tujuan penelitian ini adalah untuk mengetahui kegiatan pengelolaan sediaan farmasi, alat kesehatan dan bahan medis habis pakai berdasarkan Permenkes RI Nomor 72 Tahun 2016 di RS X Kabupaten Bekasi. Penelitian Analisa Pengelolaan Sediaan Farmasi, Alat Kesehatan dan Bahan Medis Habis Pakai menggunakan pendekatan yang bersifat yuridis normatif, yaitu dengan mengkaji atau menganalisa data sekunder yang berupa bahanbahan hukum terutama bahan hukum primer dan bahan hukum sekunder dengan memahami hukum sebagai seperangkat peraturan atau norma-norma positif di dalam sistem perundang-undangan yang mengatur mengenai kehidupan manusia dan didukung dengan kenyataan di lapangan. Hasil penelitian ini yaitu kegiatan pengelolaan sediaan farmasi, alat kesehatan dan bahan medis habis pakai di RS X Kabupaten Bekasi sudah sesuai dengan Permenkes RI Nomor 72 Tahun 2016 tentang standar pelayanan kefarmasian di Rumah Sakit yaitu mulai dari kegiatan pemilihan, perencanaan kebutuhan, pengadaan, penerimaan, penyimpanan, pendistribusian, pemusnahan dan penarikan sediaan farmasi, alat kesehatan dan bahan medis habis pakai, pengendalian dan administrasi.
\end{abstract}

Kata Kunci : Kegiatan Pengelolaan Sedian Farmasi, Alat Kesehatan dan Bahan Medis Habis Pakai, Permenkes RI Nomor 72 Tahun 2016 


\section{PENDAHULUAN}

Menurut Undang-Undang Nomor 36 Tahun 2009 tentang Kesehatan, Upaya kesehatan adalah setiap kegiatan dan/atau serangkaian kegiatan yang dilakukan secara terpadu, terintregasi dan berkesinambungan untuk memelihara dan meningkatkan derajat kesehatan masyarakat dalam bentuk pencegahan penyakit, peningkatan kesehatan, pengobatan penyakit, dan pemulihan kesehatan oleh pemerintah dan/atau masyarakat.

Rumah sakit adalah salah satu dari sarana kesehatan tempat menyelenggarakan upaya kesehatan. Upaya kesehatan diselenggarakan dengan pendekatan pemeliharaan, peningkatan kesehatan, pencegahan penyakit, penyembuhan penyakit dan pemulihan kesehatan yang dilaksanakan secara menyeluruh, terpadu dan berkesinambungan ( Charles, 2003).

Pelayanan yang ada di rumah sakit salah satunya yaitu pelayanan kefarmasian. Pelayanan kefarmasian harus dilakukan sesuai dengan standar pelayanan kefarmasian rumah sakit. Menurut Permenkes RI Nomor 72 Tahun 2016 tentang Standar Pelayanan Kefarmasian Di Rumah Sakit disebutkan bahwa Standar Pelayanan Kefarmasian adalah tolok ukur yang dipergunakan sebagai pedoman bagi tenaga kefarmasian dalam menyelenggarakan pelayanan kefarmasian. Pelayanan Kefarmasian di Rumah Sakit merupakan bagian yang tidak terpisahkan dari sistem pelayanan kesehatan Rumah Sakit yang berorientasi kepada pelayanan pasien, penyediaan Sediaan Farmasi, Alat Kesehatan, dan Bahan Medis Habis Pakai yang bermutu dan terjangkau bagi semua lapisan masyarakat termasuk pelayanan farmasi klinik.

Menurut penelitian Fais et al ( 2018 ) tentang gambaran persediaan obat di gudang farmasi RSUD Syekh Yusuf Gowa, mutu pelayanan yang diberikan rumah sakit sangat berpengaruh terhadap mutu pelayanan rumah sakit adalah pengelolaan obat yang dilakukan oleh rumah sakit. Pengelolaan obat perlu untuk dilakukan untuk mencegah terjadinya kekurangan obat (stock out), kelebihan obat (over stock), dan pembelian obat secara cito. Hasil penelitian menunjukkan bahwa pengelolaan persediaan obat di gudang farmasi RSUD Syekh Yusuf Gowa sudah cukup efektif, tetapi ada beberapa faktor yang dapat mempengaruhi kekosongan obat. Hal ini terlihat dari beberapa komponen Input (Sarana terutama gudang penyimpanan yang kurang representatif), Proses (ketidakkonsistenan terhadap penggunaan sediaan, perencanaan yang kurang teliti, suhu ruangan yang berubah-ubah mempengaruhi sediaan yang ada, keterlambatan pelaporan sediaan yang kosong dan kelalaian petugas yang mengakibatkan sediaan menjadi rusak dan expired) dan Output (sudah sesuai dengan kebutuhan).

Pengelolaan perbekalan farmasi dan alat kesehatan juga bertujuan untuk pengamanan dalam artian agar persediaan tidak terganggu oleh kerusakan, pemborosan, penggunaan tanpa hak, pencurian dan penyusutan yang tidak wajar lainnya. Selain itu dari sisi pembiayaan pengelolaan perbekalan farmasi dan alat kesehatan bertujuan agar dalam operasionalisasinya ada efesiensi pembiayaaan. Oleh karena itu, pengelolaan sediaan farmasi dan alat kesehatan dalam sistem kesehatan nasional mesti didukung oleh regulasi yang akuntabel dan operasional serta sumber daya yang memadai ( Suharni, 2016 ).

Berdasarkan latar belakang di atas maka peneliti tertarik untuk melakukan penelitian dengan judul analisa kegiatan pengelolaan sediaan farmasi, bahan medis habis pakai dan alat kesehatan berdasarkan Permenkes RI Nomor 72 Tahun 2016 di RS X Kabupaten Bekasi.

\section{METODE PENELITIAN}

A. OBJEK PENELITIAN

Penelitian yang dilakukan kaitannya dalam penulisan ini termasuk dalam kategori/jenis penelitian hukum normatif. Objek penelitian pada penelitian ini adalah kegiatan pengelolaan sediaan farmasi, alat kesehatan dan bahan medis habis pakai di RS X Kabupaten Bekasi.

\section{B. LOKASI PENELITIAN}

Lokasi penelitian tentang kegiatan pengelolaan sediaan farmasi, alat kesehatan dan bahan medis habis pakai dilakukan di RS X Kabupaten Bekasi.

\section{SPESIFIKASI PENELITIAN}

Spesifikasi dalam penelitian ini adalah deskriptif analisis, yaitu penelitian yang mendeskripsikan secara terperinci fenomena sosial yang menjadi pokok permasalahan. Suatu penelitian deskriptif dimaksudkan untuk memberikan data yang seteliti mungkin tentang penerapan aturan pemerintah tentang standar pelayanan farmasi rumah sakit ( pengelolaan sediaan farmasi, alat kesehatan dan bahan medis habis pakai di RS X Kabupaten Bekasi ). 


\section{METODE PENDEKATAN}

Penelitian analisa pengelolaan sediaan farmasi, alat kesehatan dan bahan medis habis pakai menggunakan pendekatan yang bersifat yuridis normatif, yaitu dengan mengkaji atau menganalisa data sekunder yang berupa bahan-bahan hukum terutama bahan hukum primer dan bahan hukum sekunder dengan memahami hukum sebagai seperangkat peraturan atau norma-norma positif di dalam sistem perundang-undangan yang mengatur mengenai kehidupan manusia dan didukung dengan kenyataan di lapangan

\section{E. SUMBER DATA}

Penelitian hukum yang bersifat normatif selalu menitikberatkan pada sumber data primer dan data sekunder. Data sekunder pada penelitian dapat dibedakan menjadi bahan-bahan hukum primer, bahan hukum sekunder dan bahan hukum tersier. Data sekunder sebagai data utama dan data primer digunakan sebagai data pendukung.

1. Data Primer

Data Primer diperoleh secara langsung di lapangan melalui pengamatan dan wawancara terhadap penanggung jawab gudang farmasi RS rawat inap dan rawat jalan.

2. Data Sekunder

a. Bahan Hukum Primer yaitu peraturan perundang - undangan, dalam hal ini peneliti menggunakan bahan hukum primer berupa :

1) Undang-Undang Nomor 40 Tahun 2009 tentang Rumah Sakit (Lembaran Negara Republik Indonesia Tahun 2009 Nomor 153, Tambahan Lembaran Negara Republik Indonesia Nomor 5072)

2) Undang-Undang Nomor 36 Tahun 2009 tentang Kesehatan ( Lembaran Negara Republik Indonesia Tahun 2009 Nomor 144, Tambahan Lemabaran Negara Republik Indonesia Nomor 5063)

3) Peraturan Menteri Kesehatan Republik Indonesia Nomor 72 Tahun 2016 Tentang Standar Pelayanan Kefarmasian Di Rumah Sakit ( Berita Negara Republik Indonesia Tahun 2017 Nomor 49 )

\section{b. Bahan Hukum Sekunder}

Bahan Hukum Sekunder yaitu bahan-bahan yang erat hubungannya dengan bahan hukum primer dan dapat membantu menganalisis dan memahami bahan hukum primer. Pendapat para sarjana mengenai kebijakan publik, literatur-literatur yang berkaitan dengan masalah Standar Pelayanan Farmasi RS ( kegiatan Pengelolaan Sediaan Farmasi, Alat Kesehatan dan Bahan Medis Habis Pakai).

c. Bahan Hukum Tersier

Bahan Hukum Tersier yaitu bahan-bahan yang memberikan informasi tentang bahan hukum primer dan bahan sekunder. Kamus hukum, jurnal penelitian dan internet.

\section{F. METODE PENGUMPULAN DATA}

Dalam hal ini digunakan metode bola salju ( snowball-methode ) yaitu tehnik penentuan sampel yang mula-mula jumlahnya kecil, kemudian membesar. Ibarat bola salju yang menggelinding yang lamalama menjadi besar. Data primer (lapangan), dikumpulkan dengan menggunakan pedoman untuk melakukan wawancara. Wawancara dilakukan terhadap sumber informasi yang telah ditentukan sebelumnya dengan berpedoman pada pedoman wawancara, sehingga wawancara yang dilakukan merupakan wawancara yang difokuskan (focus interview). Wawancara dalam penelitian ini akan dilakukan terhadap sumber informasi yang terjun langsung pada obyek tertentu yang berkaitan dengan permasalahan dalam penelitian ini. Langkah selanjutnya, kepada subyek penelitian diajukan beberapa butir pertanyaan. Hasil dari wawancara merupakan data primer yang mendukung data sekunder

\section{G. METODE ANALISIS}

Metode analisa data menggunakan analisa data kualitatif dengan cara menguraikan kenyataankenyataan yang ada berdasarkan hasil penelitian lalu diinterpretasikan secara sistematis dengan persoalan yang ada terutama tentang kebijakan yang mengatur kegiatan pengelolaan sediaan farmasi, alat kesehatan dan bahan medis habis pakai. Apa yang dinyatakan oleh responden secara lisan, baik berupa jawaban atau tanggapan serta pendapat, dianalisis dan ditafsirkan/diinterpretasikan, sehingga akan menghasilkan suatu data deskriptif, yaitu data yang menggambarkan keadaan objek atau peristiwa yang diteliti 


\section{HASIL, ANALISA DATA DAN PEMBAHASAN}

A. Pemilihan

Tim Farmasi dan Terapi (TFT) menyusun formularium rumah sakit mengacu pada formularium nasiaonal. Formularium rumah sakit disepakati oleh staf medis dan ditetapkan oleh direktur rumah sakit. Tim Farmasi dan Terapi membuat rekapitulasi pemakaian obat setiap tahunya. Setelah melakukan rekapitulasi pemakaian obat setiap tahunnya tim farmasi dan terapi menggolongkan obat berdasarkan slow moving dan fast moving. Selanjutnya tim farmasi dan terapi melakukan rapat dengan staf medis guna membuat formularium rumah sakit. Tim Farmasi dan Terapi (TFT) menyusun formularium rumah sakit mengacu pada formularium nasiaonal. Formularium rumah sakit disepakati oleh staf medis dan ditetapkan oleh direktur rumah sakit.

Berdasarkan Permenkes RI NO 7 Tahun 2016 tentang Standar Pelayanan Kefarmasian disebutkan bahwa Formularium Rumah Sakit disusun mengacu kepada Formularium Nasional. Formularium Rumah Sakit merupakan daftar Obat yang disepakati staf medis, disusun oleh Komite/Tim Farmasi dan Terapi yang ditetapkan oleh Pimpinan Rumah Sakit. Formularium Rumah Sakit harus tersedia untuk semua penulis Resep, pemberi Obat, dan penyedia Obat di Rumah Sakit. Evaluasi terhadap Formularium Rumah Sakit harus secara rutin dan dilakukan revisi sesuai kebijakan dan kebutuhan Rumah Sakit

B. Perencanaan Kebutuhan

Tim farmasi rumah sakit membuat perencanaan kebutuhan obat berdasarkan:

a. Anggaran yang tersedia.

b. Penetapan prioritas.

c. Sisa persediaan.

d. Data pemakaian periode yang lalu.

e. Waktu tunggu pemesanan.

f. Rencana pengembamgan.

g. Permintaan obat dari setiap ruangan pelayanan.

Berdasarkan Permenkes RI NO 7 Tahun 2016 tentang Standar Pelayanan Kefarmasian disebutkan bahwa Perencanaan dilakukan untuk menghindari kekosongan Obat dengan menggunakan metode yang dapat dipertanggungjawabkan dan dasar-dasar perencanaan yang telah ditentukan antara lain konsumsi, epidemiologi, kombinasi metode konsumsi dan epidemiologi dan disesuaikan dengan anggaran yang tersedia. Pedoman perencanaan harus mempertimbangkan: anggaran yang tersedia; penetapan prioritas; sisa persediaan; data pemakaian periode yang lalu; waktu tunggu pemesanan; dan rencana pengembangan

C. Pengadaan

\begin{tabular}{|c|c|}
\hline Instalasi Farmasi Rawat Inap & Instalasi Farmasi Rawat Jalan \\
\hline $\begin{array}{l}\text { Petugas gudang mendata } \\
\text { stock minimal di buku }\end{array}$ & $\begin{array}{l}\text { Petugas gudang mendata } \\
\text { stock minimal di buku }\end{array}$ \\
\hline $\begin{array}{l}\text { Mendata permintaan dari } \\
\text { setiap unit ruangan }\end{array}$ & $\begin{array}{l}\text { Mendata permintaan dari } \\
\text { IHC (In House CliniC) }\end{array}$ \\
\hline $\begin{array}{l}\text { Di Print Out oleh Petugas } \\
\text { Gudang serta ditanda tangani } \\
\text { oleh kepala gudang }\end{array}$ & $\begin{array}{c}\text { Di Print Out oleh Petugas } \\
\text { Gudang serta ditanda tangan } \\
\text { oleh kepala gudang }\end{array}$ \\
\hline $\begin{array}{l}\text { Khusus obat prekursor, } \\
\text { psikotropika, narkotika, } \\
\text { insulin, dan vaksin harus ada }\end{array}$ & $\begin{array}{l}\text { Khusus obat prekursor, } \\
\text { psikotropika, narkotika, } \\
\text { insulin, dan vaksin harus ada }\end{array}$ \\
\hline
\end{tabular}


Berdasarkan Permenkes RI NO 7 Tahun 2016 tentang Standar Pelayanan Kefarmasian disebutkan bahwa Pengadaan merupakan kegiatan yang dimaksudkan untuk merealisasikan perencanaan kebutuhan. Pengadaan yang efektif harus menjamin ketersediaan, jumlah, dan waktu yang tepat dengan harga yang terjangkau dan sesuai standar mutu. Pengadaan merupakan kegiatan yang berkesinambungan dimulai dari pemilihan, penentuan jumlah yang dibutuhkan, penyesuaian antara kebutuhan dan dana, pemilihan metode pengadaan, pemilihan pemasok, penentuan spesifikasi kontrak, pemantauan proses pengadaan, dan pembayaran. Untuk memastikan Sediaan Farmasi, Alat Kesehatan, dan Bahan Medis Habis Pakai sesuai dengan mutu dan spesifikasi yang dipersyaratkan maka jika proses pengadaan dilaksanakan oleh bagian lain di luar Instalasi Farmasi harus melibatkan tenaga kefarmasian.

D. Penerimaan

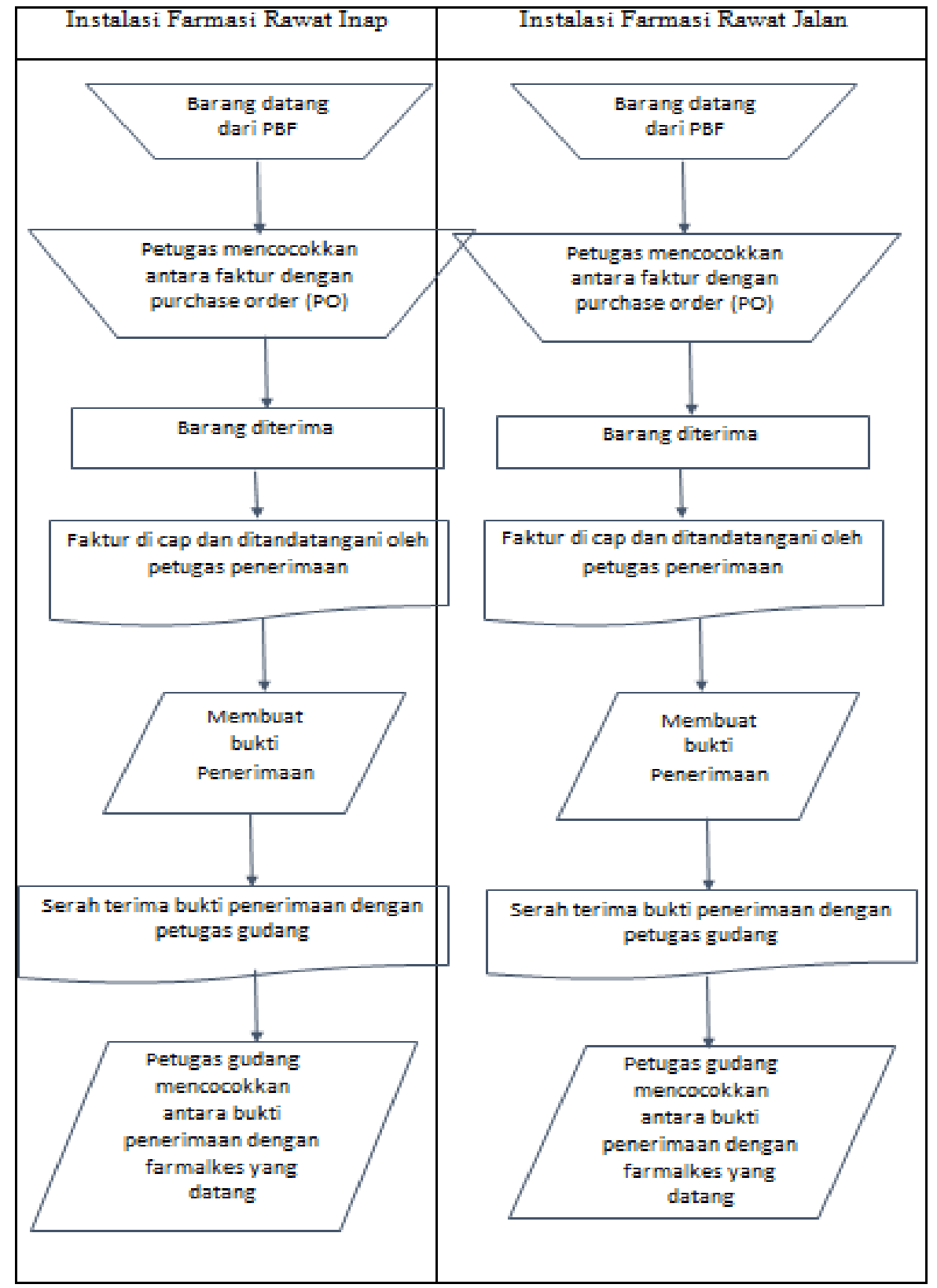

Berdasarkan Permenkes RI NO 7 Tahun 2016 tentang Standar Pelayanan Kefarmasian disebutkan bahwa Penerimaan merupakan kegiatan untuk menjamin kesesuaian jenis, spesifikasi, jumlah, mutu, waktu penyerahan dan harga yang tertera dalam kontrak atau surat pesanan dengan kondisi fisik yang diterima. Semua dokumen terkait penerimaan barang harus tersimpan dengan baik. 
Jurnal Inkofar * Volume 1 No. 2 Desember 2019 * ISSN: 2615-3645 (Print) / 2581-2920 (Online)

Tersedia secara online di: http://www.politeknikmeta.ac.id/meta/ojs/

E. Penyimpanan

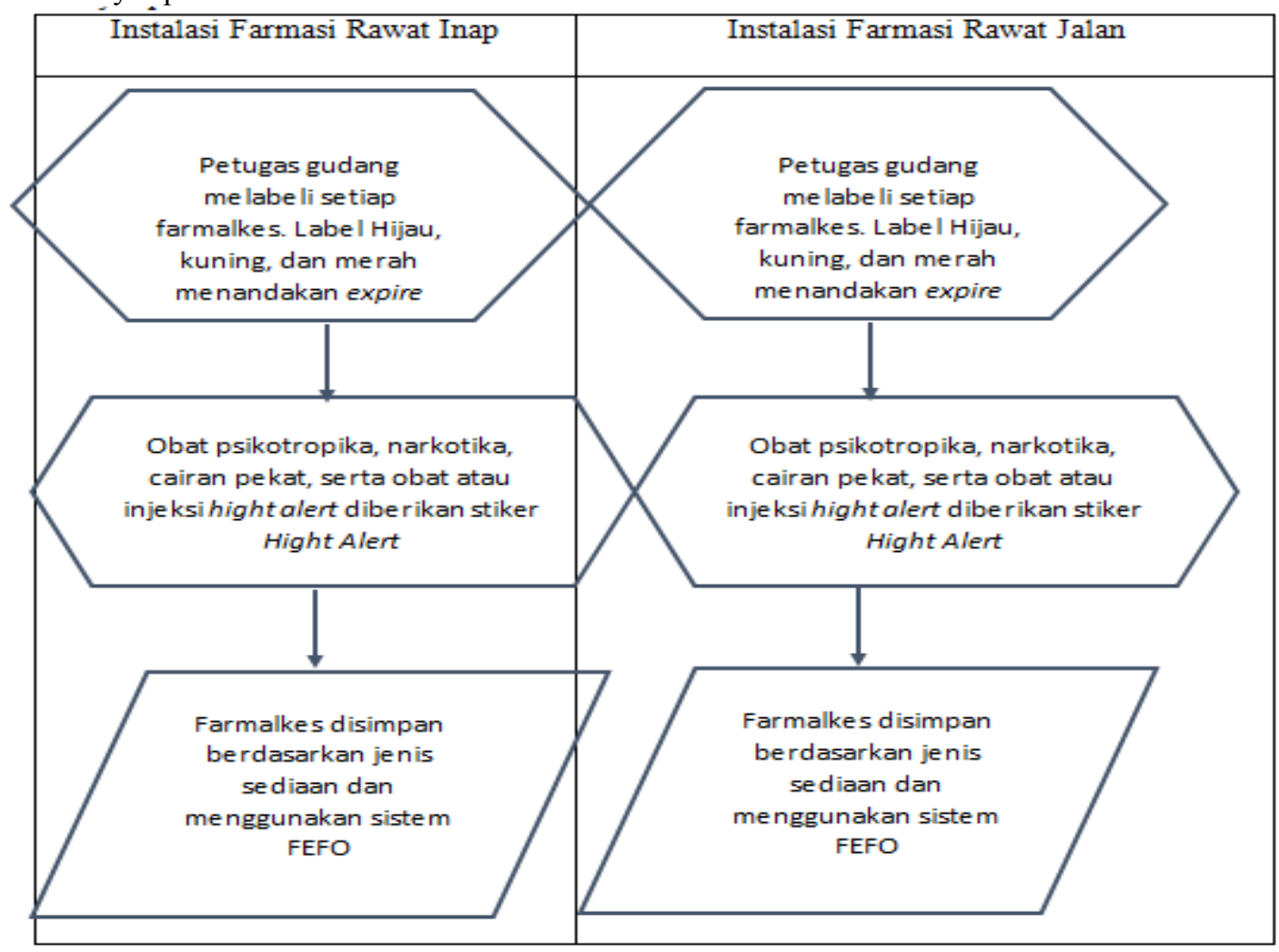

Berdasarkan Permenkes RI NO 7 Tahun 2016 tentang Standar Pelayanan Kefarmasian disebutkan bahwa setelah barang diterima di Instalasi Farmasi perlu dilakukan penyimpanan sebelum dilakukan pendistribusian. Penyimpanan harus dapat menjamin kualitas dan keamanan Sediaan Farmasi, Alat Kesehatan, dan Bahan Medis Habis Pakai sesuai dengan persyaratan kefarmasian. Persyaratan kefarmasian yang dimaksud meliputi persyaratan stabilitas dan keamanan, sanitasi, cahaya, kelembaban, ventilasi, dan penggolongan jenis Sediaan Farmasi, Alat Kesehatan, dan Bahan Medis Habis Pakai.

F. Pendistribusian

\begin{tabular}{|c|c|c|}
\hline Instalasi Farmasi Rawat Inap & \multicolumn{2}{|l|}{ Instalasi Farmasi Rawat Jalan } \\
\hline $\begin{array}{l}\text { Farmalkes di distribusikan } \\
\text { ke Instalasi Farmasi } \\
\text { Rawat Inap, Depo Farmasi } \\
\text { Eye Center, Cathlba, dan } \\
\text { Laboratorium, serta } \\
\text { ruangan perawatan }\end{array}$ & \multicolumn{2}{|l|}{$\begin{array}{c}\text { Farmalkes di distribusikan } \\
\text { ke Instalasi Farmasi } \\
\text { Rawat Jalan, Depo } \\
\text { Farmasi IGD dan IHC (In } \\
\text { House Clinic) }\end{array}$} \\
\hline Di input dan di print out & \multicolumn{2}{|l|}{ Di input dan di print out } \\
\hline $\begin{array}{l}\text { Serah terima farmalkes dari gudang } \\
\text { ke unit yang dituju dan } \\
\text { ditandatangani oleh pihak gudang } \\
\text { dan pihak kepala unit yang dituju }\end{array}$ & $\begin{array}{c}\text { Serah te rima farmalkes dari gu } \\
\text { ke unit yang dituju dan } \\
\text { ditandatangani ole h pihak gud } \\
\text { dan pihak kepala unit yang dit }\end{array}$ & $\begin{array}{l}\text { lang } \\
\text { ang } \\
\text { uju }\end{array}$ \\
\hline
\end{tabular}


Berdasarkan Permenkes RI NO 7 Tahun 2016 tentang Standar Pelayanan Kefarmasian disebutkan bahwa Distribusi merupakan suatu rangkaian kegiatan dalam rangka menyalurkan/menyerahkan Sediaan Farmasi, Alat Kesehatan, dan Bahan Medis Habis Pakai dari tempat penyimpanan sampai kepada unit pelayanan/pasien dengan tetap menjamin mutu, stabilitas, jenis, jumlah, dan ketepatan waktu. Rumah Sakit harus menentukan sistem distribusi yang dapat menjamin terlaksananya pengawasan dan pengendalian Sediaan Farmasi, Alat Kesehatan, dan Bahan Medis Habis Pakai di unit pelayanan.

G. Pemusnahan dan Penarikan Sediaan Farmasi, Alat Kesehatan dan Bahan Medis Habis Pakai

Proses kegiatan pemusnahan di gudang farmasi rawat inap dan rawat jalan sama tidak ada perbedaannya. Dalam pemusnahan farmalkes dilakukan setiap 5 tahun sekali serta pemusnahan ini dilakukan bukan hanya karena farmalkes expire date namun farmalkes rusak ataupun mutunya tidak sesuai dengan standar. Sebelum melakukan pemusnahan barang yang sudah expire date didata farmalkes yang telah expire date maupun yang mendekati expire date yang tidak bisa diretur, setelah didata farmalkes tersebut kemudian dipisahkan sesuai bentuk sediaannya, lalu ditaruh di dalam kardus yang sudah ditutup rapat serta diberi label "dimusnahkan", lalu disimpan di dalam ruangan khusus (ruangan karantika) sebelum obat dimusnahkan. Setelah itu dibuatlah jadwal, metode, dan tempat pemusnahan. Kemudian dibuatlah surat pemohonan ke Balai Besar POM, setelah dikonfirmasi oleh pihak Balai POM petugas gudang mengeluarkan farmalkes yang siap di musnahkan sekaligus menyaksikan pemusnahan tersebut. Kemudian dibuat berita acara pemusnahan dengan saksi petugas farmasi dan managemen rumah sakit, di dalam isi berita acara pemusnahan terdapat nama farmalkes, jumlah, nomor bacth, nomor registrasi, dan bentuk sediaan tersebut. Berita acara pemusnahan harus ditandatangani oleh kepala instalisasi, saksi dari petugas farmasi, dan managemen rumah sakit. Khusus untuk pemusnahan obat ataupun injeksi psikotropika dan narkotika berbeda sedikit yaitu tempat penyimpanannya harus terpisah dengan farmalkes lainnya. Penanggung jawab instalasi farmasi menyampaikan surat pemberitahuan dan pemohonan saksi kepada Dinas Kesehatan Kabupaten/Kota dan/atau Balai Besar/Balai Pengawas Obat dan Makanan setempat. Lalu obat psikotropika dan narkotika dilakukan pemastian kebenaran secara organoleptis oleh saksi sebelum pemusnahan. Berita cara pemusnahan tersebut sebanyak 3 rangkap dan tembusannya disampaikan kedapa Kepala Dinkes Kabupaten/Kota dan Kepala badan/Balai POM.

Berdasarkan Permenkes RI NO 7 Tahun 2016 tentang Standar Pelayanan Kefarmasian disebutkan bahwa Pemusnahan dan penarikan Sediaan Farmasi, Alat Kesehatan, dan Bahan Medis Habis Pakai yang tidak dapat digunakan harus dilaksanakan dengan cara yang sesuai dengan ketentuan peraturan perundang-undangan yang berlaku.

Pemusnahan dilakukan untuk Sediaan Farmasi, Alat Kesehatan, dan Bahan Medis Habis Pakai bila: produk tidak memenuhi persyaratan mutu; telah kadaluwarsa; tidak memenuhi syarat untuk dipergunakan dalam pelayanan kesehatan atau kepentingan ilmu pengetahuan; dan/atau dicabut izin edarnya.

Tahapan pemusnahan terdiri dari: membuat daftar Sediaan Farmasi, Alat Kesehatan, dan Bahan Medis Habis Pakai yang akan dimusnahkan; menyiapkan Berita Acara Pemusnahan; mengoordinasikan jadwal, metode dan tempat pemusnahan kepada pihak terkait; menyiapkan tempat pemusnahan; dan melakukan pemusnahan disesuaikan dengan jenis dan bentuk sediaan serta peraturan yang berlaku.

H. Pengendalian

Dalam pengendalian farmalkes obat digudang farmasi rawat inap dilakukanya stock opname setiap bulan sekali. Wilayah stock opname gudang farmasi cukup luas seperti ke ruangan setiap poli, ruagan perawatan, ruangan operasi, ruangan hemodialis, laboratorium, radiologi, fisioterapi, ESWL, dan thalassemia. Data stock opname tersebut diinput dikomputer dan dilaporkan ke managemen rumah sakit. Namun untuk stock opname konsinyasi seperti di eye center dan cahtlab dilakukan oleh penanggung jawab depo farmasi eye center dan cathlab serta vendor masing - masing distributor tersebut. Lalu dilaporkan ke kepala instalasi farmasi dan managemen rumah sakit.

Dalam pengendalian farmalkes obat digudang farmasi rawat jalan dilakukanya stock opname setiap bulan sekali. Wilayah stock opname gudang farmasi rawat jalan hanya gudang farmasi rawat jalan dan IHC, namun untuk stock opname IHC petugas farmasi rawat jalan mengunjungi setiap perusahanyang bekerja sama rumah sakit. Data stock opname tersebut diinput dikomputer dan dilaporkan ke managemen rumah sakit. 
Berdasarkan Permenkes RI NO 7 Tahun 2016 tentang Standar Pelayanan Kefarmasian disebutkan bahwa Pengendalian dilakukan terhadap jenis dan jumlah persediaan dan penggunaan Sediaan Farmasi, Alat Kesehatan, dan Bahan Medis Habis Pakai. Pengendalian penggunaan Sediaan Farmasi, Alat Kesehatan, dan Bahan Medis Habis Pakai dapat dilakukan oleh Instalasi Farmasi harus bersama dengan Komite/Tim Farmasi dan Terapi di Rumah Sakit. Cara untuk mengendalikan persediaan Sediaan Farmasi, Alat Kesehatan, dan Bahan Medis Habis Pakai adalah: melakukan evaluasi persediaan yang jarang digunakan (slow moving); melakukan evaluasi persediaan yang tidak digunakan dalam waktu tiga bulan berturut-turut (death stock); Stok opname yang dilakukan secara periodik dan berkala

I. Administrasi

Petugas gudang farmasi melakukan pencataan setiap obat - obatan datang yaitu seperti pencataan obat hight alert, psikotropika dan narkotika, dan vaksin. Semua di catat berapa jumlah obat, no bacth, dan expire datenya. Untuk pelaporan stock opname dilakukan setiap sebulan sekali, selain itu pelaporan pemakaian psikotropika dan narkotika, obat - obatan hight alert, dan vaksin juga dicatat pemakaiannya serta dilaporkan setiap bulannya. Untuk pemakaian vaksin harus terdapat nama pasien dan nomor rekam medis pasien setiap pemakaiannya.

Berdasarkan Permenkes RI NO 7 Tahun 2016 tentang Standar Pelayanan Kefarmasian disebutkan bahwa Administrasi harus dilakukan secara tertib dan berkesinambungan untuk memudahkan penelusuran kegiatan yang sudah berlalu.

\section{KESIMPULAN}

RS X yang berada di Kabupaten Bekasi telah melakukan kegiatan pengelolaan sediaan farmasi, alat kesehatan dan bahan medis habis pakai berdasarkan Permenkes RI Nomor 72 Tahun 2016 yaitu kegiatannya diantaranya pemilihan, perencanaan kebutuhan, pengadaan, penerimaan, penyimpanan, pendistribusian, pemusanahan dan penarikan sediaan farmasi, alat kesehatan dan bahan medis habis pakai, pengendalian, dan administrasi.

\section{DAFTAR PUSTAKA}

Undang-Undang Nomor 40 Tahun 2009 tentang Rumah Sakit (Lembaran Negara Republik Indonesia Tahun 2009 Nomor 153, Tambahan Lembaran Negara Republik Indonesia Nomor 5072)

Undang-Undang Nomor 36 Tahun 2009 tentang Kesehatan ( Lembaran Negara Republik Indonesia Tahun 2009 Nomor 144, Tambahan Lemabaran Negara Republik Indonesia Nomor 5063)

Peraturan Menteri Kesehatan Republik Indonesia Nomor 72 Tahun 2016 Tentang Standar Pelayanan Kefarmasian Di Rumah Sakit ( Berita Negara Republik Indonesia Tahun 2017 Nomor 49 )

Fais Satrianegara. 2018. Gambaran Pengelolaan Persediaan Obat Di Gudang Farmasi RSUD SyekhYusuf Gowa. Makasar : Al-Sihah : Public Health Science Jurnal

M. Suharni. 2016. Pengelolaan Sediaan Farmasi dan Alat Kesehatan terkait HIV/AIDS,pada : http://www.kebijakanaidsindonesia.net/id/artikel/artikel-tematik/1547-pengelolaan-sediaanfarmasi-dan-alat-kesehatan-terkait-hiv-dan-aids di akses tanggal 6 Agustus 2019. 